\title{
Behavioral Determinants of Cannabinoid Self-Administration in Old World Monkeys
}

\author{
William S John', Thomas J Martin² and Michael A Nader*,I \\ 'Department of Physiology and Pharmacology, Wake Forest School of Medicine, Winston-Salem, NC, USA; '2Department of Anesthesiology, Wake \\ Forest School of Medicine, Winston-Salem, NC, USA
}

\begin{abstract}
Reinforcing effects of $\Delta^{9}$-tetrahydrocannabinol (THC), the primary active ingredient in marijuana, as assessed with self-administration (SA), has only been established in New World primates (squirrel monkeys). The objective of this study was to investigate some experimental factors that may enhance intravenous SA of THC and the cannabinoid receptor (CBR) agonist CP 55940 in Old World monkeys (rhesus and cynomolgus), a species that has been used extensively in biomedical research. In one experiment, male rhesus monkeys ( $N=9)$ were trained to respond under a fixed-ratio 10 schedule of food presentation. The effects of CP 55940 (I.0-10 Hg/ $/ \mathrm{kg}$, i.v.) and THC (3.0$300 \mathrm{\mu g} / \mathrm{kg}$, i.v.) on food-maintained responding and body temperature were determined in these subjects prior to giving them access to self-administer each drug. Both drugs dose-dependently decreased food-maintained responding. CP 55940 (0.00 I-3.0 Mg/kg) functioned as a reinforcer in three monkeys, whereas THC $(0.01-10 \mu g / k g)$ did not have reinforcing effects in any subject. CP 55940 was least potent to decrease food-maintained responding in the monkeys in which CP 55940 functioned as a reinforcer. Next, THC was administered daily to monkeys until tolerance developed to rate-decreasing effects. When THC SA was reexamined, it functioned as a reinforcer in three monkeys. In a group of cocaine-experienced male cynomolgus monkeys $(N=4)$, THC SA was examined under a second-order schedule of reinforcement; THC functioned as reinforcer in two monkeys. These data suggest that SA of CBR agonists may be relatively independent of their rate-decreasing effects in Old World monkeys. Understanding individual differences in vulnerability to THC SA may lead to novel treatment strategies for marijuana abuse.

Neuropsychopharmacology (2017) 42, I522-1530; doi:I0.1038/npp.20 I7.2; published online I February 2017
\end{abstract}

\section{INTRODUCTION}

Marijuana (Cannabis sativa) is the most commonly abused illicit drug in the United States, with an estimated 4.2 million people that meet DSM criteria for dependence or abuse (SAMHSA, 2014). Moreover, marijuana use has been steadily increasing among persons $>18$ years old, but not among 12-17 year olds (Azofeifa et al, 2016). As a result, there is a need for more preclinical research to better understand the pharmacological, environmental, and biological determinants of cannabis use in order to develop more effective treatment strategies for cannabis use disorder. A major obstacle to such progress has been the difficulty in demonstrating the reinforcing effects of $\Delta^{9}$-tetrahydrocannabinol (THC), the main psychoactive component of marijuana, using self-administration (SA) procedures in animals. Successful efforts have been limited to one laboratory using squirrel monkeys (Tanda et al, 2000; Justinova et al, 2003). Every other THC SA attempt using other nonhuman primate (NHP) species (ie, rhesus monkeys) or rodents has been

*Correspondence: Dr MA Nader, Department of Physiology and Pharmacology, Wake Forest School of Medicine, Medical Center Boulevard, 546 NRC, Winston-Salem, NC 27|57-I083, USA. Tel: + |336-7|3-7|72; Fax: + 336-7|3-7|80, E-mail:mnader@wakehealth.edu Received 3 August 2016; revised 23 December 2016; accepted 30 December 2016; accepted article preview online 6 January 2017 unsuccessful (Kaymakcalan, 1972, 1973; Pickens et al, 1973; Harris et al, 1974; Leite and Carlini, 1974; Carney et al, 1977; Van Ree et al, 1978; Mansbach et al, 1994; Li et al, 2012; Lefever et al, 2014).

It is currently unknown whether previous unsuccessful attempts in rhesus monkeys were due to methodological factors or species-related differences between squirrel (New World) and rhesus (Old World) monkeys. Thus, one goal of the present study was to make THC available to rhesus monkeys under similar SA conditions as used in squirrel monkeys, including schedule of reinforcement and vehicle preparation. With THC being a low efficacy, partial agonist at the $\mathrm{CB}_{1} / \mathrm{CB}_{2}$ receptors, the present study also evaluated the reinforcing effects of the synthetic bicyclic cannabinoid receptor (CBR) analog, CP 55940, a high efficacy, full $\mathrm{CB}_{1} / \mathrm{CB}_{2}$ agonist, to allow for a better understanding of the role of pharmacological efficacy at the CBR in SA. Furthermore, the characterization of individual qualitative and quantitative differences in CBR agonist SA was examined. One hypothesis to explain the failure of THC to function as a reinforcer among experimental animals involves the initial rate-decreasing effects of THC, which may mask the reinforcing effects, such that subjects less sensitive to the rate-decreasing effects of CP 55940 and THC would have greater rates of SA of both drugs. To test this hypothesis, the potency of both drugs to 
decrease food-maintained responding was correlated with rates of SA.

The rate-decreasing effects of cannabinoids represent a variable that could be modified to facilitate acquisition of SA. For instance, the data suggest that through repeated drug exposure, tolerance may develop to the aversive/ratedecreasing effects of THC (Lindgren et al, 1981; PerezReyes et al, 1991; Lepore et al, 1995; Kirk and de Wit, 1999; Valjent and Maldonado, 2000; Ghozland et al, 2002; Scherma et al, 2016). Whether tolerance to THC-induced ratedecreasing effects will enhance THC SA is an empirical question that has not been documented in animal models; this was examined in the present study. We hypothesized that tolerance would develop to the rate-decreasing effects of THC and this would result in increases in rates of THC SA compared with the initial assessment.

Another behavioral variable that can influence drug-selfadministration is the schedule of reinforcement, especially for drugs that are not considered highly efficacious reinforcers (Nader et al, 2015). Schedules under which the frequency of reinforcement is relatively independent of response rate may be advantageous for studying THC selfadministration. Thus, the present study also examined THC $\mathrm{SA}$ in another group of monkeys in which responding was maintained under a second-order schedule of reinforcement. It was hypothesized that responding under this reinforcement schedule would lead to higher THC SA compared with vehicle SA.

\section{MATERIALS AND METHODS}

\section{Subjects}

Nine individually housed adult male rhesus (Macaca mulatta) and four pair housed adult male cynomolgus (M. fascicularis) monkeys served as subjects. Six rhesus monkeys had histories of methamphetamine or cocaine SA (John et al, 2015a,b) but had been abstinent for $\sim 4$ months before these experiments began. Three rhesus monkeys did not have a SA history prior to this study (Table 1). All four cynomolgus monkeys had extensive cocaine histories ( $~ 8$ years) at the initiation of this study. Each monkey was fitted with an aluminum collar (Model B008, Primate Products, Redwood City, CA) and trained to sit in a primate restraint chair (Primate Products). Monkeys were fed sufficient standard laboratory chow (Purina LabDiet 5045, St Louis, MO) to maintain healthy body weights (determined by veterinary staff). Animal housing and all experimental procedures were performed in accordance with the 2011 National Research Council Guidelines for the Care and Use of Mammals in Neuroscience and Behavioral Research and were approved by the Animal Care and Use Committee of Wake Forest University.

\section{Surgery}

Subjects were prepared with chronic indwelling venous catheters under aseptic conditions as previously described (John et al, 2015a, b). All monkeys were implanted subcutaneously with a transponder (Model IPTT-300; Bio Medic Data Systems, Seaford, DE) to non-invasively measure body temperature.
Table I Ages, Weights, and Self-Administration Histories for Rhesus Monkeys

\begin{tabular}{lccc}
\hline Subject & Age (years) & Weight $(\mathbf{k g})$ & Drug SA history $(\mathbf{m g} / \mathbf{k g})$ \\
\hline R-1567 & 20 & 10.0 & 134.9 (methA) \\
R-1690 & 12 & 12.2 & 373.9 (methA) \\
R-1691 & 10 & 8.7 & 366.8 (methA) \\
R-1693 & 11 & 11.7 & 283.7 (methA) \\
R-1710 & 9 & 9.8 & 68.7 (cocaine) \\
R-1711 & 9 & 11.2 & 10.3 (cocaine) \\
R-1682 & 15 & 13.8 & 0 \\
R-1713 & 9 & 14.4 & 0 \\
R-1756 & 19 & 13.3 & 0 \\
\hline
\end{tabular}

\section{Apparatus}

Behavioral sessions were carried out in ventilated, soundattenuating chambers $(1.5 \times 0.74 \times 0.76 \mathrm{~m}$; Med Associates, East Fairfield, VT) designed to accommodate a primate chair. Two photo-optic switches $(5 \mathrm{~cm}$ wide; Model 117-1007; Stewart Ergonomics, Furlong, PA) were located on one side of the chamber with a horizontal row of three stimulus lights positioned $14 \mathrm{~cm}$ above each switch. A food receptacle was located between the switches and connected with a Tygon tube to a pellet dispenser (Med Associates) located on the top of the chamber. A peristaltic infusion pump (7531-10, Cole-Parmer Co., Chicago, IL) for delivering drug injections at a rate of $\sim 1.5 \mathrm{ml}$ per $10 \mathrm{~s}$ was also located on the top of the chamber. White noise was continuously present to mask extraneous noise.

\section{Experiment 1: Self-Administration of THC and CP 55940 and Potential Behavioral Phenotypes Related to Reinforcement in Rhesus Monkeys}

Behavioral phenotype assessments. Rhesus monkeys were trained to respond under a fixed-ratio (FR) 10, 60-s time-out (TO) schedule of food presentation. Sessions began with illumination of a white stimulus light above one of two photo-optic switches in the chamber, counterbalanced between monkeys. Ten consecutive responses emitted on the appropriate switch delivered a 1.0-g banana-flavored food pellet (Bio-Serv, Frenchtown, NJ) accompanied by extinction of the white light and illumination of a red light above the food receptacle for $3 \mathrm{~s}$. Responses emitted on the alternate switch had no programmed consequence. Sessions lasted $60 \mathrm{~min}$ or until 30 reinforcers were obtained, whichever occurred first. Once responding was stable (three consecutive sessions with response rates within $\pm 20 \%$ of the mean rate for those sessions, with no trends), noncontingent injections of CP $55940(1.0-10 \mu \mathrm{g} / \mathrm{kg}$, i.v.) and THC $(3.0-300 \mu \mathrm{g} / \mathrm{kg}$, i.v.) were administered one minute prior to operant sessions. All doses were tested 2-3 times for each monkey; CP 55940 was tested first in all monkeys. Body temperature was taken non-invasively using the implanted telemetry device (Bio Medic Data Systems) immediately prior to CP 55940 or THC administration and then again 60 -min following the start of the session. 
Substitution studies. After determining the CP 55940 and THC dose-response curves and when stable food-maintained responding was re-established, i.v. injections of vehicle (1.0\% Tween 80 and $1.0 \%$ ethanol in sterile water) and different doses of CP $55940(0.001-3.0 \mu \mathrm{g} / \mathrm{kg})$ and $\mathrm{THC}$ $(0.01-10 \mu \mathrm{g} / \mathrm{kg})$ were substituted for food pellets for at least five sessions and until responding was stable. Dose-response curves for CP 55940 SA were determined first in all monkeys followed by dose-response curves for THC, with the exception of one monkey that was only studied with $\mathrm{CP}$ 55940 and another monkey that only completed the doseresponse curve for THC. Completion of each FR delivered an i.v. infusion $(\sim 0.5 \mathrm{ml}$ in $3 \mathrm{~s})$, followed by a $60 \mathrm{~s}$ TO; sessions ended after a maximum of 30 injections or 60 min elapsed, whichever occurred first. There was a return to foodmaintained responding for at least three sessions between substitutions of different drug doses. Doses were tested in quasi-random order for each monkey, such that the highest dose was not tested first in any monkey.

\section{Experiment 2. Effects of Chronic THC Treatment on THC SA}

Following substitution studies for both drugs, responding was maintained by food presentation for at least five sessions and until stable. Next, the $\mathrm{ED}_{50}$ for THC to decrease foodmaintained responding, individually determined for each monkey, was administered non-contingently (i.v.) one min prior to each session for at least three sessions and until tolerance developed to the rate-decreasing effects. Tolerance was said to occur when average rates of responding were within $20 \%$ of baseline rates for three consecutive sessions. At that point, the dose for non-contingent administration was increased between one-eighth and one-half log-units, depending on the monkey, and administered for at least five sessions and until tolerance developed to those ratedecreasing effects on food-maintained responding. Once responding was stable, SA of a range of THC doses was redetermined. During this time, non-contingent THC injections $(10-100 \mu \mathrm{g} / \mathrm{kg}$, i.v.) were administered $\sim 5 \mathrm{~min}$ after SA sessions, and after the monkeys were removed from the operant chamber. Between THC dose substitutions, there was a return to food-maintained responding for at least three sessions with THC administered non-contingently, using a dose that reduced food-maintained responding to below $20 \%$ of baseline rates, prior to those sessions.

\section{Experiment 3. THC Self-Administration Under a Second-Order Schedule of Reinforcement}

Four cynomolgus monkeys had been trained to selfadminister cocaine under a second-order fixed-interval (FI) 600-s [FR 30:S] schedule of i.v. cocaine injections. At the beginning of the session, a white light was illuminated over one of the photo optic switches (counterbalanced between monkeys), which served as a discriminative stimulus. Following the completion of every 30th response (FR 30) during the $600 \mathrm{~s} \mathrm{FI}$, the white light was extinguished and a red light was illuminated for $2 \mathrm{~s}$. Once the interval elapsed, the first FR 30 completed produced an i.v. injection of cocaine delivered over $10 \mathrm{~s}$ paired with the red light. Thus, the red light served as the conditioned stimulus (CS). A 60-s
TO followed each injection, during which all lights were extinguished and responses had no scheduled consequence. Daily sessions ended after the completion of five cycles of the schedule or 90 min elapsed, whichever occurred first.

Following the determination of a cocaine dose-response curve $(3.0-560 \mu \mathrm{g} / \mathrm{kg} /$ injection), saline was substituted for the training dose of cocaine $(100 \mu \mathrm{g} / \mathrm{kg} /$ injection $)$ and the CS was turned off until responding was reduced to $20 \%$ of baseline rates for three consecutive sessions. Next, the CS was reintroduced for at least three consecutive sessions during which saline was still available for SA. When responding was stable, $3.0 \mu \mathrm{g} / \mathrm{kg}$ THC was substituted for at least seven consecutive sessions and until the overall rate of responding was stable (three consecutive sessions with response rates within $\pm 20 \%$ of the mean rate for those sessions, with no trends). A dose-response curve was determined by substituting vehicle, which included presentation of the CS, and a range of THC doses $(1.0-30 \mu \mathrm{g} / \mathrm{kg} /$ injection) in random order and for at least five consecutive sessions. There was a return to $3.0 \mu \mathrm{g} / \mathrm{kg}$ THC (except in C-7427 in which the dose was $10 \mu \mathrm{g} / \mathrm{kg}$ THC) for five consecutive sessions before a different THC dose was substituted.

\section{Data Analysis}

The primary dependent variable for the studies examining CP 55940 and THC administration on food-maintained responding was response rate (responses/second). Drug effects were expressed as a percentage of baseline responding, which was designated as three consecutive sessions of stable responding prior to the start of the study. Change in body temperature $\left({ }^{\circ} \mathrm{C}\right)$ following administration of either $\mathrm{CP}$ 55940 or THC was determined by subtracting the temperature recorded prior to the start of the session from the temperature recorded at the end of the 60 -min session. The potency of CP 55940 and THC to decrease food-maintained responding was estimated by calculating the $\mathrm{ED}_{50}$ using the linear portion of the curve that crossed 50\% reduction in baseline response rate. To calculate the relative potency of both drugs to decrease body temperature, the dose decreasing temperature by $0.5^{\circ} \mathrm{C}$ was estimated by interpolation of the data (Rodriguez and McMahon, 2014).

For SA, the primary dependent variables were the number of reinforcers earned per session and mean rate of responding. Data were expressed as the mean $( \pm S D)$ over the last three sessions for each drug dose. Dose-response curves for THC and CP 55940 were analyzed using one-way repeated-measures ANOVA; significant main effect was followed by Dunnett's multiple comparisons post hoc tests. The criterion for significance was set a priori at $p<0.05$.

\section{Drugs}

THC and CP 55940 , both obtained from the National Institute on Drug Abuse (NIDA), Bethesda, MD, were dissolved in a vehicle containing one part Tween 80 , one part ethanol and 18 parts sterile water. ( - )-Cocaine $\mathrm{HCl}$ (NIDA) was dissolved in sterile $0.9 \%$ saline. Different SA doses were studied by varying the concentration of drug available per injection. 


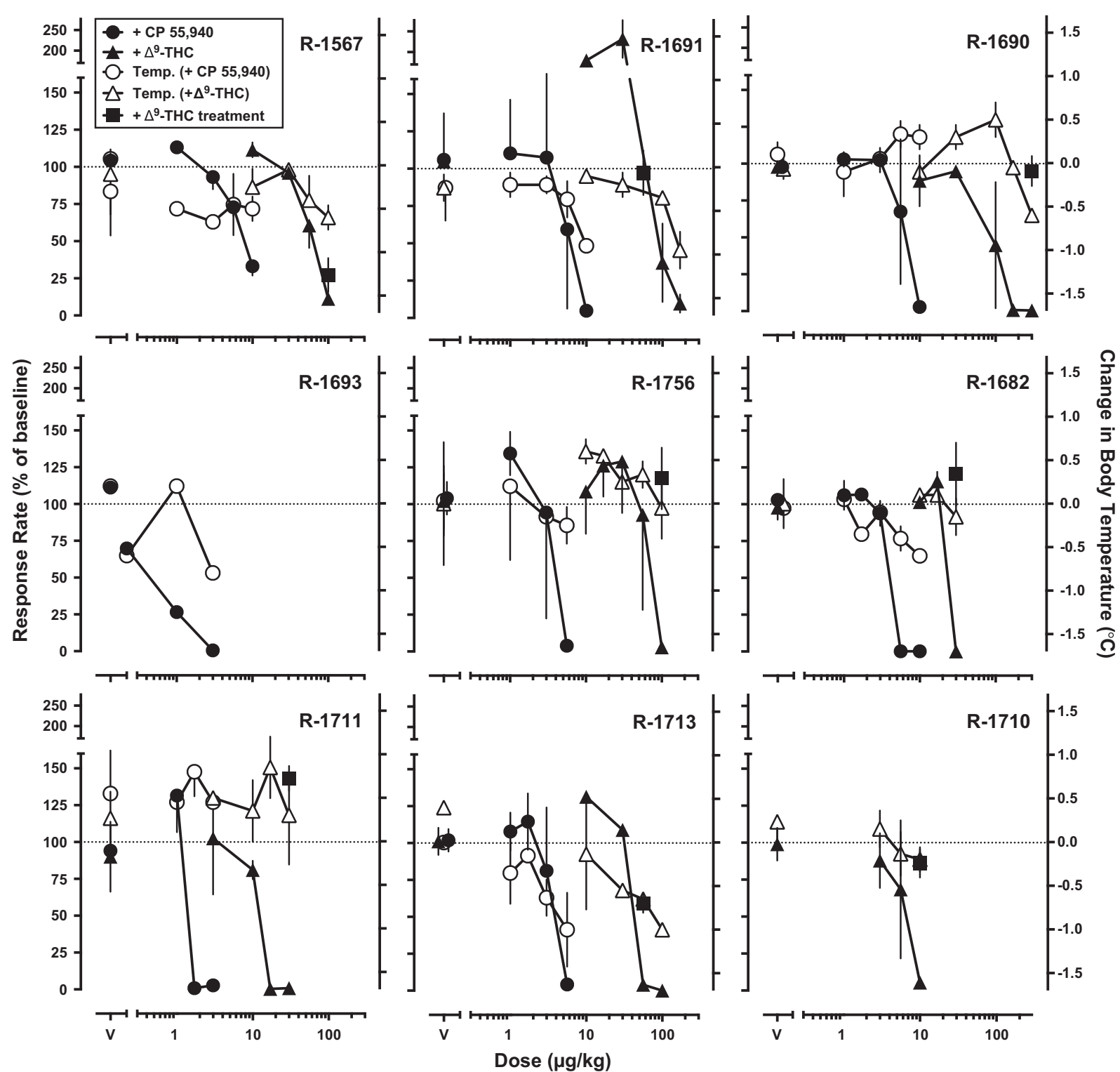

Figure I Effects of CP 55940 (circles) and $\Delta^{9}$-tetrahydrocannabinol (THC) (triangles) on food-maintained responding (filled symbols) and body temperature (open symbols) in individual mesus monkeys $(n=9)$. CP 55940 and THC were administered non-contingently I min prior to the start of the session and body temperature was recorded prior to each injection and then again 60 min following the start of the session. Tolerance to the rate-decreasing effects of THC on food-maintained responding was developed by repeated administration across consecutive sessions (filled squares). Abscissae: Dose of CP 55940 and THC in $\mu g / k g$. Left ordinate: Mean $( \pm S D)$ response rate expressed as a percentage of baseline. Right ordinate: Mean ( \pm SD) change in body temperature expressed in ${ }^{\circ} \mathrm{C}$.

\section{RESULTS}

\section{Experiment 1}

The mean $( \pm$ SEM $)$ rate of FR food-maintained responding was $1.16 \pm 0.2$ responses/s in which the maximum number of reinforcers (30) was always earned. Although two monkeys showed increases at low THC doses, mean response rates were dose-dependently decreased by non-contingent administration of CP $55940(\mathrm{~F}(5,36)=11.5 ; p<0.0001$; Figure 1, closed circles) and THC $(\mathrm{F}(5,33)=3.37 ; p<0.05$; Figure 1 , closed triangles). The mean $\mathrm{ED}_{50}$ values $(95 \%$ confidence limits) for CP 55940 and THC to decrease food-maintained responding were $5.0(3.0-6.0)$ and $67(28-100) \mu \mathrm{g} / \mathrm{kg}$, respectively. CP 55940 was $\sim 15$-fold more potent at decreasing food-maintained responding than THC. Noncontingent administration of CP 55940 and THC also produced dose-dependent reductions in body temperature, which corresponded to the rate-decreasing effects on foodmaintained responding, although individual differences were noted (Figure 1, open symbols). The dose of CP 55940 and THC that produced a $0.5^{\circ} \mathrm{C}$ decrease in body temperature $\left(\mathrm{ED}_{-0.5}{ }^{\circ} \mathrm{C}\right.$ value) was estimated to be 17 and $180 \mu \mathrm{g} / \mathrm{kg}$, respectively; CP55 940 was $~ 11$-fold more potent than THC.

When CP 55940 was substituted for food pellets, reinforcing effects were achieved in three of eight rhesus monkeys (Figure 2, closed circles; Supplementary Figure S1) as determined by repeated-measures one-way ANOVA $(\mathrm{R}-1567: \mathrm{F}(5,10)=21.76, p<0.0001 ; \mathrm{R}-1690: \mathrm{F}(5,10)=13.48$, 


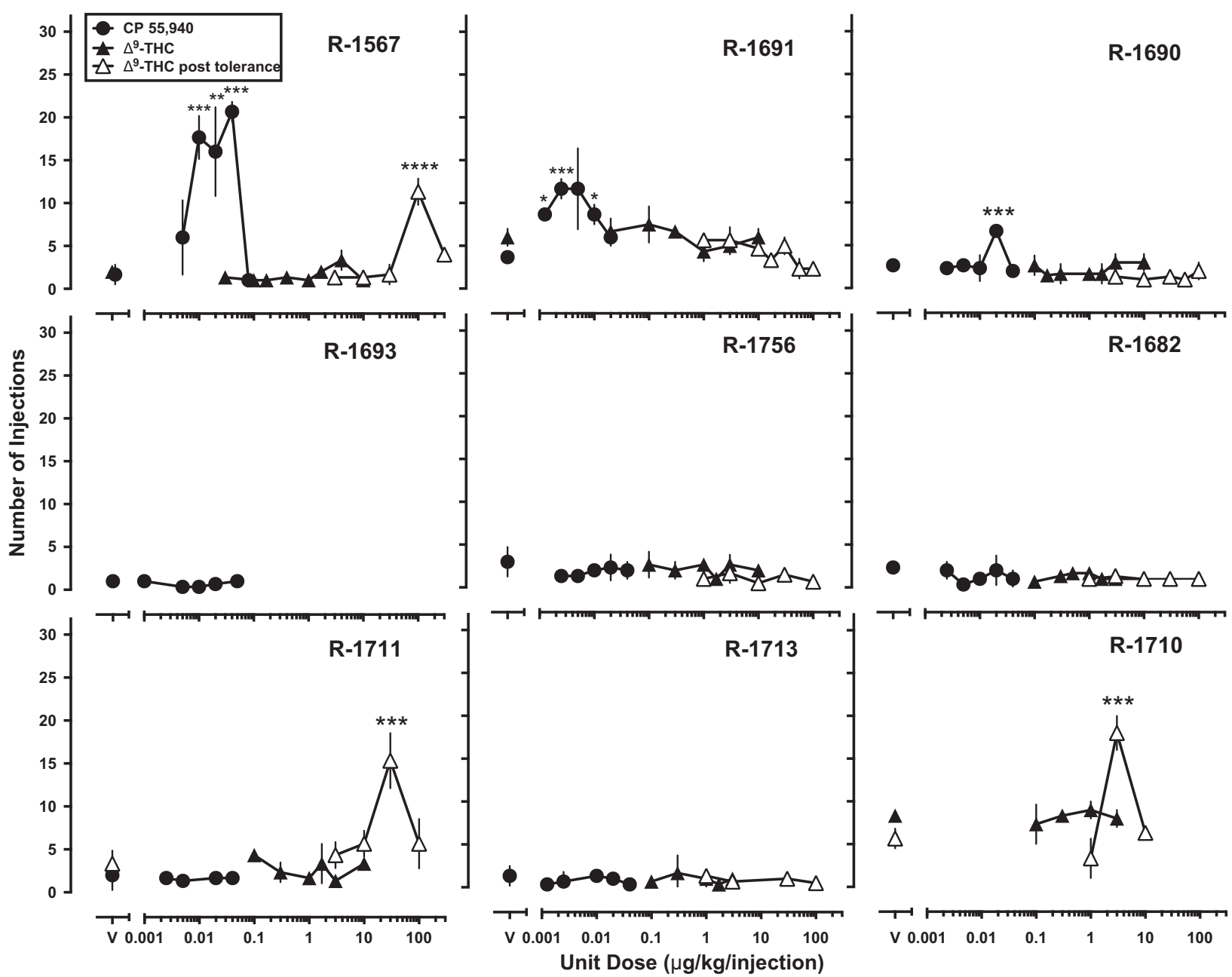

Figure 2 Self-administration dose-response curves for CP 55940 (filled circles), THC (closed triangles) and $\Delta^{9}$-tetrahydrocannabinol (THC) after the development of tolerance to rate-decreasing effects on food-maintained responding (open triangles). Abscissae: Unit dose ( $\mu \mathrm{g} / \mathrm{kg} / \mathrm{injection})$ available for selfadministration. Ordinate: Number of injections earned in the 60-min session. Data represent mean \pm SD of last three sessions. $* p<0.05$, $* * p<0.01$, ***** $p<0.00$ I, ******** $p<0.000$ I compared with vehicle.

Table 2 Relationship Between CP 55940 Potency to Decrease Food-Maintained Responding and CP 55940 Self-Administration

\begin{tabular}{lcc}
\hline Subject & ED $_{\mathbf{5 0}} \mathbf{( 9 5 \% \text { confidence interval) }}$ & Max injections (SD) \\
\hline R-1567 & $0.007(0.006-0.008)$ & $20.67(1.16)$ \\
R-169| & $0.006(0.004-0.009)$ & $11.67(1.16)$ \\
R-1690 & $0.006(0.004-0.009)$ & $6.67(0.58)$ \\
R-1693 & $0.0009(\mathrm{NA})$ & $1(0)$ \\
R-1682 & $0.003(0.001-0.01)$ & $2.0(1.73)$ \\
R-17|I & $0.001(0.0006-0.002)$ & $1.67(0.58)$ \\
R-17|3 & $0.003(0.002-0.006)$ & $1.33(0.58)$ \\
R-1756 & $0.003(0.001-0.008)$ & $2.33(1.53)$ \\
\hline
\end{tabular}

$p<0.001$; R-1691: $\mathrm{F}(5,10)=9.07, p<0.01)$. The peak injections of CP 55940 occurred at $0.04,0.02$, and $0.00125 \mu \mathrm{g} / \mathrm{kg} /$ injection for R-1567, R-1690, and R-1691, respectively. CP 55940 was least potent at decreasing food-maintained responding in the three monkeys in which the drug functioned as a reinforcer (Table 2). No relationship was found between CP 55940 reinforcing effects and CP 55940 induced changes in body temperature.

In contrast to CP 55 940, THC over a broad range of doses $(0.03-10 \mu \mathrm{g} / \mathrm{kg})$ did not maintain responding above vehicle levels, even in the three monkeys in which CP 55940 functioned as a reinforcer (Figure 2, closed triangles). In four of eight monkeys, however, THC produced transient reinforcing effects in which the number of injections earned was greater than the frequency of vehicle injections for two or more consecutive sessions (Supplementary Fig. S2).

\section{Experiment 2}

Daily administration of the $\mathrm{ED}_{50}$ dose of THC for decreasing food-maintained responding resulted in tolerance to the ratedecreasing effects within $5.25( \pm 0.75$ SEM) sessions. This dose was increased by one-eighth to one-half log units and tolerance developed to those effects within 6.17 ( \pm 1.14 SEM) sessions (Figure 1, closed squares). Following the development of tolerance to the rate-decreasing effects of THC, SA was reexamined and THC functioned as a reinforcer in three monkeys (Figure 2, open triangles; Supplementary Fig. S3), 
as determined by repeated measures one-way ANOVA $(\mathrm{R}-1710: \mathrm{F}(3,6)=65.69 ; p<0.001 ; \mathrm{R}-1567: \mathrm{F}(3,6)=95.43$; $p<0.0001$; R-1711: $\mathrm{F}(4,8)=19.47 ; p<0.001)$.

\section{Experiment 3}

Prior to the start of THC SA, monkeys responded under a second-order FI 600-s (FR 30:S) schedule of cocaine reinforcement. Cocaine dose-response curves, determined for each monkey, were represented as an inverted U-shaped function of cocaine dose (Figure 3, open squares). After saline substitution, with removal of the CS, responding declined; response-contingent presentation of the CS did not increase responding. Substituting different THC doses resulted in THC maintaining responding at significantly higher rates than vehicle in two of four subjects (Figure 3, closed triangles), with maximal rates maintained when 10 and $3.0 \mu \mathrm{g} / \mathrm{kg} /$ injection were available. All monkeys responded for the maximal number of injections available (5) for each dose of THC and vehicle except C-6526, whose mean vehicle injections was 0.0 and mean THC injections for 1.0 and $30 \mu \mathrm{g} / \mathrm{kg} /$ injection of $0.67( \pm 0.58 \mathrm{SD})$ and 2.67 $( \pm 1.53 \mathrm{SD})$, respectively.

\section{DISCUSSION}

One goal of the present study was to investigate cannabinoid SA in rhesus monkeys under similar parameters successfully used to demonstrate the reinforcing effects of cannabinoids in squirrel monkeys. We also examined behavioral phenotypes that may mediate individual differences in SA. The CBR agonist CP 55940 functioned as a reinforcer in three of eight monkeys; reinforcing effects were inversely related to CP 55 940-induced behavioral disruption. In those same monkeys, THC did not have reinforcing effects in any animal. Daily THC treatment with a dose that initially produced significant rate-decreasing effects resulted in THC functioning as a reinforcer in three monkeys. In another group of monkeys, THC functioned as a reinforcer in two of four animals responding under a second-order schedule. Across all conditions, of the 13 monkeys studied, CBR agonists functioned as reinforcers in 7 animals. Understanding these individual differences may lead to improved animal models and the identification of novel treatments for marijuana abuse.

Studies in humans show that individuals who are more sensitive to the aversive effects of cannabis were less likely to be current users (Haertzen et al, 1983; Thomas, 1996). The prominent aversive effects of cannabinoids have been demonstrated in conditioned place preference studies in rodents where several studies report that THC and synthetic CBR agonists generally induce conditioned place aversion rather than place preference, except following a period of extended drug exposure (Lepore et al, 1995; Valjent and Maldonado, 2000; Ghozland et al, 2002). Thus, one hypothesis for the lack of cannabinoid SA in experimental animals is that the aversive (rate-decreasing) effects of THC and other CBR agonists are inhibiting measures of reinforcement in macaques (and perhaps rodents) to a greater degree than is apparent in squirrel monkeys. Results with CP 55940 provide some support for this hypothesis; CP

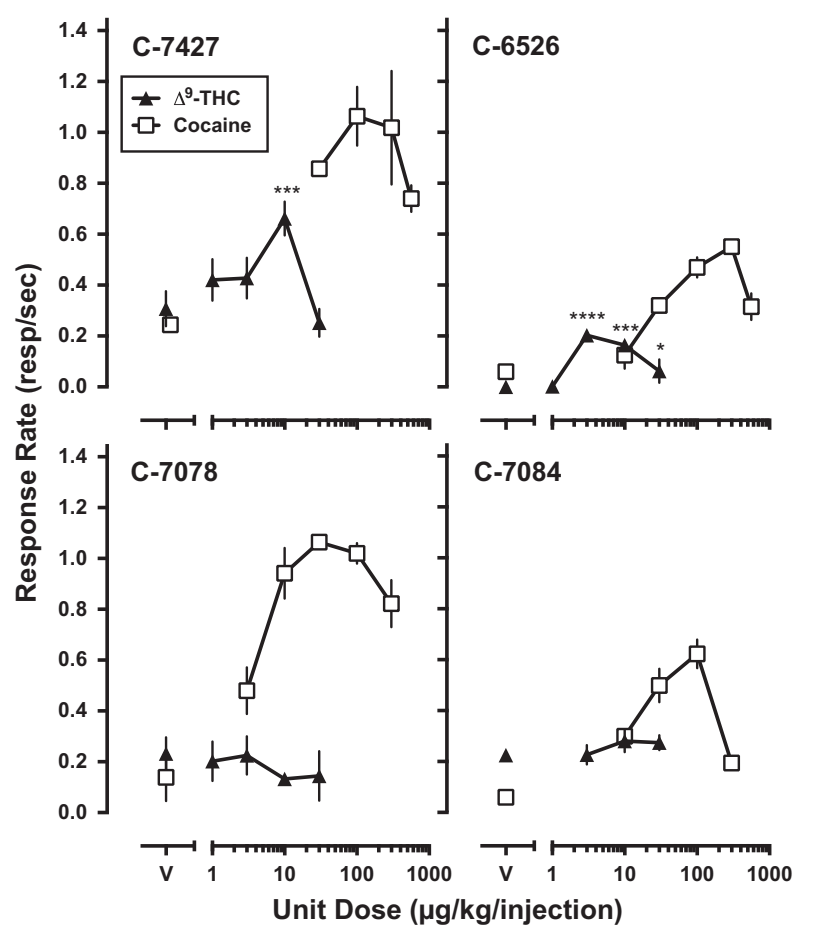

Figure 3 THC self-administration under a second-order [FI 600-s (FR 30:S)] schedule of reinforcement. Each dose was studied for a minimum of 7 sessions and until responding was stable. Data represent mean $( \pm S D)$ response rates for $\Delta^{9}$-tetrahydrocannabinol ( $\mathrm{THC}$ ) (filled triangles) and cocaine (open squares) during last 3 sessions of substitution. Abscissae: Unit dose ( $\mu \mathrm{g} / \mathrm{kg} /$ injection) available for self-administration. Ordinate: Mean overall rate of responding (responses/sec). C-7427: $F(4,8)=14.94$, $p<0.001 ; \mathrm{C}-6526: \mathrm{F}(4,8)=41.72, \quad p<0.001$. Post-hoc: ${ }^{*} p<0.05$, **** $p<0.001$, ******* $p<0.0001$.

55940 functioned as a reinforcer in the three monkeys least sensitive to the drug's rate-disruptive effects. However, in those same three monkeys, THC was also the least potent to decrease rates of food-maintained responding, but THC did not function as a reinforcer in any monkey following the initial determination.

These results suggest that there may be a relationship between $\mathrm{CB}_{1}$ receptor agonist efficacy and reinforcing effects considering the low-efficacy $\mathrm{CB}_{1}$ partial agonist THC did not function as reinforcer in the same monkeys that the high efficacy $\mathrm{CB}_{1}$ full agonist CP55940 did. However, due to the large number of $\mathrm{CB}_{1}$ receptors in the central nervous system (Gifford et al, 1999), THC often produces the same maximum effect as that obtained with high efficacy $C_{1}$ agonists for a range of behaviors including drug discrimination, antinociception, and locomotor activity (Fan et al, 1994; McMahon, 2011); however, exceptions have been noted for hypothermic effects (Paronis et al, 2012). Paronis et al (2012) noted that the $\mathrm{CB}_{1}$ full agonist AM2389 produced larger reductions in body temperature in mice compared with THC, providing in vivo evidence that THC was a partial agonist. In the present study, we noted similar effects on body temperature following THC and the full $\mathrm{CB}_{1}$ agonist CP 55940 , although these effects were substantially smaller than noted by Paronis et al (2012) in mice. On the basis of the present findings, reinforcing effects may be another example of THC producing partial agonist effects in vivo. Several CBR agonist SA studies in rodents support this 
notion in which the high-efficacy CBR agonist WIN55,212, but not THC, maintained behavior above vehicle levels (Martellotta et al, 1998; Fattore et al, 2001; Lefever et al, 2014).

While these data suggest a species difference between rhesus and squirrel monkeys as it relates to the initial reinforcing effects of $\mathrm{THC}$, direct comparisons are difficult because of different behavioral baselines, route and treatment regimens (acute $v s$ chronic). For example, Kangas et al (2016) recently reported that non-contingent intramuscular administration of THC, at a dose as low as $0.03 \mathrm{mg} / \mathrm{kg}$ (ie, $30 \mu \mathrm{g} / \mathrm{kg}$ ) could disrupt reversal learning in squirrel monkeys. However, doses up to $100 \mu \mathrm{g} / \mathrm{kg}$ (i.m.) were required to decrease food-maintained responding under a progressive-ratio schedule of reinforcement. In the present study, the $\mathrm{ED}_{50}$ for THC to decrease FR 10 food-maintained responding was $67 \mu \mathrm{g} / \mathrm{kg}(28-100 \mu \mathrm{g} / \mathrm{kg})$. Consistent with our hypothesis that THC is less disruptive in squirrel monkeys compared to rhesus monkeys, Justinova et al (2013; Supplementary Figure 1) reported significant decreases in food-maintained responding following $0.56 \mathrm{mg} / \mathrm{kg}$ (ie, $560 \mu \mathrm{g} / \mathrm{kg}$, i.v.) THC, which is $\sim 1.0$ log-units higher (ie, less potent) compared to the rhesus monkeys used in the present study. These data indicate that the reinforcing effects of THC may only be unmasked when there is a certain degree of insensitivity to the rate-decreasing effects, similar to what was shown in the present study involving CP 55940 self-administration.

To further evaluate the relationship between sensitivity to the rate-decreasing effects of THC and SA, we conducted two additional experiments. In one study, THC was administered daily in order for tolerance to develop to the rate-decreasing effects of THC. After reassessing SA, THC only functioned as a reinforcer in three animals. Interestingly, one of these subjects (R-1567) did not completely develop tolerance to the rate-decreasing effects prior to reassessing SA. This suggests that a period of pre-exposure to THC, rather than the development of tolerance to rate-decreasing effects, could be the more crucial factor for acquiring THC SA. It is also important to note that for some monkeys higher THC doses were tested following chronic THC administration compared to the initial substitution studies, making it difficult to fully determine whether tolerance development was a factor in influencing SA. Future studies should determine if other experimental manipulations (eg, lengthen TO or change the schedule to progressive-ratio) could yield more robust THC SA.

The range of doses we tested during chronic administration was gradually increased because we noted in preliminary studies that monkeys would not develop tolerance to the rate-decreasing effects of THC under the present dosing regimen if the initial dose decreased responding below 20\% of baseline. Thus, it remains possible that higher daily THC doses would have yielded more robust THC SA. Furthermore, no observational signs of physical withdrawal were noted during daily THC administration, which is consistent with previous studies (Beardsley et al, 1986; Stewart and McMahon, 2010). It remains to be determined whether higher THC doses and longer treatment regimens would enhance the likelihood of THC SA. An important factor to consider, and highlighted in Beardsley et al (1986), is that disruptions in operant behavior are more sensitive measures of THC withdrawal than observations of physical withdrawal symptoms. Thus, if we had tested higher THC doses, we may have noted disruptions in operant behavior following discontinuation of THC treatment.

A second method to address the role of sensitivity to ratedisruptive effects and SA was to use a schedule of reinforcement in which response rates and reinforcement frequency were not directly related. Two of four monkeys self-administering THC under a second-order FI 600-s (FR 30:S) schedule showed reinforcing effects at doses similar to those that resulted in reinforcing effects in squirrel monkeys responding under a second-order schedule (Justinova et al, 2008); there was no apparent relationship between rates of responding maintained by cocaine and the ability for THC to have reinforcing effects. Mansbach et al (1994) also used an FI 600 s schedule but did not report any evidence that THC maintained responding higher than vehicle presentation. There are several differences between these two studies that may account for the somewhat discrepant findings. An obvious difference is the use of an FI $600 \mathrm{~s} v s$ a second-order schedule, which would suggest that use of conditioned stimuli may enhance the likelihood of THC self-administration. A second difference is the maximum number of injections per session (12 vs 5) and a third possibility is the baseline drug that was used to train SA, PCP vs cocaine. In the Mansbach et al (1994) study, when THC was substituted for PCP, it resulted in lower reinforcement frequency than vehicle substitution, while reinforcement frequency was not lower than vehicle substitution in the present study. Clearly, much work remains to better determine the conditions necessary to obtain robust THC self-administration.

The failure of THC to function as a reinforcer in the majority of subjects following the development of tolerance to rate-decreasing effects suggests other factors may be involved. One possible explanation is that THC reinforcement was related to individual differences in THC pharmacokinetics and/or metabolism following daily THC exposure. However, studies in animals and humans have shown that chronic THC exposure does not significantly change THC metabolism or disposition (Dewey et al, 1973; McMillan et al, 1973; Siemens and Kalant, 1974; Martin et al, 1976; Hunt and Jones, 1980; Ginsburg et al, 2014). Even so, this possibility cannot be rejected and should be investigated with particular attention to individual differences in correspondence with other behavioral endpoints related to reinforcement.

It is important to note that there was a relationship between drug history and CBR agonist SA in that three of the four monkeys that had an extensive methamphetamine SA history were the subjects in which CP 55940 functioned as a reinforcer, while THC functioned as a reinforcer in two of four cynomolgus monkeys with a cocaine history. Previous studies in squirrel monkeys demonstrated that a drug SA history was not necessary for acquiring robust levels of THC self-administration (Justinova et al, 2003). At present, the role of pharmacological history in the acquisition of CBR self-administration remains unclear. A better understanding of the importance of drug history, schedule of reinforcement, behavioral, and physiological biomarkers related to pharmacological sensitivity to CBR agonist selfadministration are needed to establish a reliable preclinical model of cannabinoid abuse. 


\section{FUNDING AND DISCLOSURE}

This research was supported by grants from NIH/NIDA: R37 DA10584 (MAN), P50 DA06634 (MAN), F31 DA041825 (WSJ) and T32 AA-007565 (WSJ). The authors declare no conflict of interest.

\section{ACKNOWLEDGMENTS}

We thank Michael Coller and Susan Nader for assistance throughout this project and Paul Czoty, Linda Porrino and Jenny Wiley for helpful discussions. We also thank Drs. Gianluigi Tanda and Amy Newman for their assistance with initiating these experiments. WSJ, TJM and MAN designed the studies. WSJ conducted the experiments and analyzed the data. WSJ, TJM and MAN wrote the manuscript.

\section{REFERENCES}

Azofeifa A, Mattson ME, Schauer G, McAfee T, Grant A, Lyerla R (2016). National estimates of marijuana use and related indicators - National Survey on Drug Use and Health, United States, 2002-2014. MMWR Surveill Summ 65: 1-25.

Beardsley PM, Balster RL, Harris LS (1986). Dependence on tetrahydrocannabinol in rhesus monkeys. J Pharmacol Exp Ther 239: 311-319.

Carney JM, Uwaydah IM, Balster RL (1977). Evaluation of a suspension system for intravenous self-administration of water insoluble substances in the rhesus monkey. Pharmacol Biochem Behav 7: 357-364.

Dewey WL, McMillan DE, Harris LS, Turk RF (1973). Distribution of radioactivity in brain of tolerant and nontolerant pigeons treated with ${ }^{3} \mathrm{H}-\Delta^{9}$-tetrahydrocannabinol. Biochem Pharmacol 22: 399-405.

Fan F, Compton DR, Ward S, Melvin L, Martin BR (1994). Development of cross- tolerance between delta 9-tetrahydrocannabinol, CP 55,940 and WIN 55,212. J Pharmacol Exp Ther 271: 1383-1390.

Fattore L, Cossu G, Martellotta CM, Fratta W (2001). Intravenous self-administration of the cannabinoid CB1 receptor agonist WIN 55,212-2 in rats. Psychopharmacology 156: 410-416.

Ghozland S, Mathews H, Simonin F, Filliol D, Kieffer BL, Maldonado R (2002). Motivational effects of cannabinoids are mediated by - and k-opioid receptors. J Neurosci 22: 1146-1154.

Gifford AN, Bruneus M, Lin S, Goutopoulos A, Makriyannis A, Volkow ND et al (1999). Potentiation of the action of anandamide on hippocampal slices by the fatty acid amide hydrolase inhibitor, palmitylsulphonyl fluoride (AM 374). Eur J Pharmacol 383: 9-14.

Ginsburg BC, Hruba L, Zaki A, Javors MA, McMahon LR (2014). Blood levels do not predict behavioral or physiological effects of $\Delta^{9}$-tetrahydrocannabinol in rhesus monkeys with different patterns of exposure. Drug Alcohol Depend 139: 1-8.

Haertzen CA, Kocher TR, Miyasato K (1983). Reinforcements from the first drug experience can predict later drug habits and/or addiction: results with coffee, cigarettes, alcohol, barbiturates, minor and major tranquilizers, stimulants, marijuana, hallucinogens, heroin, opiates and cocaine. Drug Alcohol Depend 11: 147-165.

Harris RT, Waters W, McLendon D (1974). Evaluation of reinforcing capability of $\Delta^{9}$-tetrahydrocannabinol in monkeys. Psychopharmacologia 37: 23-29.

Hunt CA, Jones RT (1980). Tolerance and disposition of tetrahydrocannabinol in man. J Pharmacol Exp Ther 215: 35-44.

John WS, Banala AK, Newman AH, Nader MA (2015a). Effects of buspirone and the dopamine D3 receptor compound PG619 on cocaine and methamphetamine self-administration in rhesus monkeys using a food-drug choice paradigm. Psychopharmacology (Berl) 232: 1279-1289.

John WS, Newman AH, Nader MA (2015b). Differential effects of the dopamine D3 receptor antagonist PG01037 on cocaine and methamphetamine self-administration in rhesus monkeys. Neuropharmacology 92: 34-43.

Justinova Z, Mascia P, Wu H-Q, Secci ME, Redhi GH, Panlilio L et al (2013). Reducing cannabinoid abuse and preventing relapse by enhancing endogenous brain levels of kynurenic acid. Nat Neurosci 16: 1652-1661.

Justinova Z, Munzar P, Panlilio LV, Yasar S, Redhi GH, Tanda G et al (2008). Blockade of THC-seeking behavior and relapse in monkeys by the cannabinoid $\mathrm{CB}(1)$-receptor antagonist rimonabant. Neuropsychopharmacology 33: 2870-2877.

Justinova Z, Tanda G, Redhi GH, Goldberg SR (2003). Self-administration of delta(9)-tetrahydrocannabinol (THC) by drug naive squirrel monkeys. Psychopharmacology 169: 135-140.

Kangas BD, Leonard MZ, Shukla VG, Alapafuja SO, Nikas SP, Makriyannis A et al (2016). Comparisons of $\Delta^{9}$-tetrahydrocannabinol and anandamide on a battery of cognition-related behavior in nonhuman primates. J Pharmacol Exp Ther 357: 125-133.

Kaymakcalan S (1972). Physiology and psychological dependence on THC in rhesus monkeys. In: Paton WDM, Crown J(eds). Cannabis and its Derivatives. Oxford University Press: London. pp 142-149.

Kaymakcalan S (1973). Tolerance to and dependence on cannabis. Bull Narc 25: 39-47.

Kirk JM, De Wit H (1999). Responses to oral delta9-tetrahydrocannabinol in frequent and infrequent marijuanausers. Pharmacol Biochem Behav 63: 137-142.

Lefever TW, Marusich JA, Antonazzo KR, Wiley JL (2014). Evaluation of WIN 55,212-2 self-administration in rats as a potential cannabinoid abuse liability model. Pharmacol Biochem Behav 118: 30-35.

Leite JR, Carlini EA (1974). Failure to obtain "cannabis directed behavior" and abstinence syndrome in rats chronically treated with cannabis sativa extracts. Psychopharmacologia 36: 133-145.

Lepore M, Vorel SR, Lowinson J, Gardner EL (1995). Conditioned place preference induced by D9-tetrahydrocannabinol: comparison with cocaine, morphine, and food reward. Life Sci 56: 2073-2080.

Li J-X, Koek W, France CP (2012). Interactions between $\Delta(9)$ tetrahydrocannabinol and heroin: self-administration in rhesus monkeys. Behav Pharmacol 23: 754-761.

Lindgren JE, Ohlsson A, Agurell S, Hollister L, Gillespie H (1981). Clinical effects and plasma levels of delta 9-tetrahydrocannabinol (delta 9-THC) in heavy and light users of cannabis. Psychopharmacology 74: 208-212.

Mansbach RS, Nicholson KL, Martin BR, Balster RL (1994). Failure of $\Delta^{9}$-tetrahydrocannabinol and CP 55,940 to maintain intravenous self administration under a fixed-interval schedule in rhesus monkeys. Behav Pharmacol 5: 219-225.

Martellotta MC, Cossu G, Fattore L, Gessa GL, Fratta W (1998). Self-administration of the cannabinoid receptor agonist WIN 55,212-2 in drug-naive mice. Neuroscience 85: 327-330.

Martin BR, Dewey WL, Harris LS, Beckner JS (1976). ${ }^{3} \mathrm{H}-\Delta(9)$ tetrahydrocannabinol tissue and subcellular distribution in the central nervous system and tissue distribution in peripheral organs of tolerant and nontolerant dogs. J Pharmacol Exp Ther 196: $128-144$.

McMahon LR (2011). Chronic delta9-tetrahydrocannabinol treatment in rhesus monkeys: differential tolerance and crosstolerance among cannabinoids. Br J Pharmacol 162: 1060-1073.

McMillan DE, Dewey WL, Turk RF, Harris LS, McNeil JH (1973). Blood levels of 3H-D9-tetrahydrocannabinol and its metabolites in tolerant and nontolerant pigeons. Biochem Pharmacol 22: 383-397. 
Nader MA, Lile JA, John WS, Czoty PW (2015). Nonhuman primate models of abuse liability. In Weinbauer GF, Vogel F (eds). "Primate Biologics Research at a Crossroads". Waxmann Publishing Co: Muenster, Germany. pp 37-59.

Paronis CA, Nikas SP, Shukla VG, Makriyannis A (2012). $\Delta^{9}$-Tetrahydrocannabinol acts as a partial agonist/antagonist in mice. Behav Pharmacol 23: 802-805.

Perez-Reyes M, White WR, McDonald SA, Hicks RE, Jeffcoat AR, Cook CE (1991). The pharmacologic effects of daily marijuana smoking in humans. Pharmacol Biochem Behav 40: 691-694.

Pickens R, Thompson T, Muchow DC. Cannabis and phencyclidine self-administered by animals (1973). Goldfarb L, Hoffmeister F (eds). Psychic dependence [Bayer-Symposium IV]. Springer: Berlin Heidelberg New York. pp 78-86.

Rodriguez JS, McMahon LR (2014). JWH-018 in rhesus monkeys: differential antagonism of discriminative stimulus, rate-decreasing, and hypothermic effects. Eur J Pharmacol 740: 151-159.

SAMHSA (2014). Substance Abuse and Mental Health Services Administration. Results from the 2013 National Survey on Drug Use and Health: Overview of findings. NSDUH series $\mathrm{H}-$ 48, HHS Publication No. (SMA) 14-4863. Substance Abuse and Mental Health Services Administration: Rockville, MD.
Scherma M, Dessì C, Muntoni AL, Lecca S, Satta V, Luchicchi A et al (2016). Adolescent $\Delta^{9}$-tetrahydrocannabinol exposure alters WIN55,212-2 self-administration in adult rats. Neuropsychopharmacology 41: 1416-1426.

Siemens AJ, Kalant H (1974). Metabolism of delta1-tetrahydrocannabinol by rats tolerant to cannabis. Can J Physiol Pharmacol 52: 1154-11566.

Stewart JL, McMahon LR (2010). Rimonabant-induced $\Delta^{9}$-THC withdrawal in rhesus monkeys: discriminative stimulus effects and other withdrawal signs. $J$ Pharmacol Exp Ther 334: 347-356.

Tanda G, Munzar P, Goldberg SR (2000). Self-administration behavior is maintained by the psychoactive ingredient of marijuana in squirrel monkeys. Nat Neurosci 3: 1073-1074.

Thomas H (1996). A community survey of adverse effects of cannabis use. Drug Alcohol Depend 42: 201-207.

Valjent E, Maldonado R (2000). A behavioural model to reveal place preference to $\Delta^{9}$-tetrahydrocannabinol in mice. Psychopharmacology 147: 436-438.

Van Ree JM, Slangen JL, de Wied D (1978). Intravenous selfadministration of drugs in rats. J Pharmacol Exp Ther 204: 547-557.

Supplementary Information accompanies the paper on the Neuropsychopharmacology website (http://www.nature.com/npp) 